\title{
The influence of rectification sharpness on the quality of motor fuels
}

\author{
M. S. Rogalev \& R. Z. Magaril \\ Department of Oil and Gas Processing, \\ Tyumen State Oil and Gas University, Russia
}

\begin{abstract}
At present, the production of motor fuels is associated with the compounding of products of reforming, isomerization, catalytic cracking, hydrocracking and hydrotreating. The quality of the components of motor fuels obtained in the above processes strongly depends on the rectification sharpness of raw materials and the stabilization of end-products. The existing lack of rectification sharpness worsens the economic parameters of the production of motor fuels and their operational and environmental properties. This problem results from the insufficiently effective interaction of the vapor and liquid phases in the contact devices of distillation towers. Here, we prove the necessity of taking into account the diffusion of key components of distillates between the vapor and liquid phases and the surface phenomena at the phase boundary in contact devices. Increasing the operating pressure in distillation towers and the introduction of surface-active substances per residue leads to a high degree of separation of distillates during their rectification. This technique has successfully been tested on the manufacturing facilities of a number of primary oil refining and gas processing plants. An industrial implementation of these findings will enable the improvement of the economic parameters of production of motor fuels and their operational and environmental properties.

Keywords: quality of motor fuels, rectification, rectification sharpness, process of mass transfer, surfactants.
\end{abstract}

\section{Introduction}

The basic theoretical applications for the distillation process in the oil and gas processing industry are described in detail in [1-6].

This process is used in almost all stages of the production of components of motor fuels $[3,4,6]$. 
We studied data for rectification sharpness that is described in the scientific literature $[3,4,6]$. Overlay light petroleum fractions have a primary distillation range from $50^{\circ} \mathrm{C}$ to $100^{\circ} \mathrm{C}$, and their selection of potential content is $88-92 \%$ [3, $6]$. In the stabilization process of oil distillation fractions or components of motor fuels, $5 \%$ of pentane remains in the gas stabilization, and also about $5 \%$ of butane remains in the stabilized product of the rectification tower $[3,4,6]$. In the de-ethanization process of a wide fraction of light hydrocarbons, $5 \%$ of propane remains in the gas de-ethanization and about $3 \%$ of methane and ethane remains in the broad fraction of light hydrocarbons [4]. In the stabilization process of a wide fraction of light hydrocarbons, $3 \%$ of pentane remains in the overflow of the stabilization towers, and about $2 \%$ of propane and butane remains in the wide fraction of light hydrocarbons [3, 4].

The existence of rectification unsharpness reduces the quality of motor fuels produced and adversely affects the material balance of oil and gas refineries $[3,4,6]$.

The required number of contact devices, their effectiveness, and the reflux ratio of steam numbers has an influence on the rectification sharpness $[1,2,5]$. In the engineering calculations of rectification towers, the expressions of the driving force of the rectification process through the number of theoretical numbers of contact devices and the kinetics through the efficiency of the contact device are used [1]. Currently an accepted assumption is that equilibrium between the vapor and liquid phases on the contact device is achieved in the calculation of the amount required to ensure rectification sharpness of hydrocarbon mixtures. In fact, the equilibrium between the vapor and liquid phases at the interaction on the contact devices of the rectification tower is not reached. Calculation of the theoretical contact devices necessary for the rectification sharpness of hydrocarbon mixtures in the rectification tower, based on the above-presented postulation, to move to the required number of real contact devices in the rectification tower, needs the introduction of efficiency contact devices. Their number is determined based on the accumulated experience of operating industrial contact devices of this type [5,6].

To clarify the scheme the calculation of the number of contact devices for a rectification tower have been discussed and shown in [2, 6-8].

In [1-8] the effect of the influence of the change of mode of operation of the rectification tower over a wide range on the efficiency of the contact device in has been neglected. In reinforcing the clarity of the rectification tower, the rectification sharpness of hydrocarbon mixtures is determined by considering the efficiency condensing boundary components of the vapor bubbles flowing on the contact layer reflux device in a liquid. This process is largely dependent on the mode of operation of the rectification tower. On the contact devices of the rectification tower the rectification unsharpness of fractions or individual components reduces to considerable content of lighter components in the bottom part that overtops the thermodynamic equilibrium [1, 2]. This leads to a loss of light components from the product to a lower rectification tower.

We present the results of research aimed at achieving a rectification sharpness of hydrocarbon mixtures on distillates or individual components. To do this, the 
influence on the contact devices of the process of mass transfer between the components of the vapor and liquid phases strengthens the rectification tower so that it changes its mode of operation. This process is derived from the dependence of the operating parameters of the rectification process. The proposal to increase the efficiency of the process of mass transfer between the components of the vapor and liquid phases on the contact devices strengthens the rectification column. This provides a method for estimating the efficiency of the contact device of the rectification tower through an expression that includes the parameters of its operation mode. We consider the process of boiling of the light fraction from the bottom of the rectification tower. An alternative method is to speed up the process by adding a surfactant. The results of industrial testing of the proposed methods improve the efficiency of the rectification process.

\section{The description of the influence of the operating mode of the rectification towers on the process of mass transfer between components of the vapour and liquid phases on the contact part of the reinforcing devices}

Transfer of the components of the vapor phase into the liquid through the interface, which serves as the surface layer of vapor bubbles passing through the layer phlegm on the contact device of the rectification tower, can be described by Fick's first law as follows:

$$
M=\frac{D \cdot S \cdot \tau}{\delta} \cdot\left[\pi \cdot y^{\prime}-P \cdot x^{\prime}\right]
$$

where $M$ is the amount of component diffusing from the vapor phase into the liquid; $D$ is the molecular diffusion coefficient in the diffusion boundary layer; $S$ is the surface of the bubbles of the vapor phase bubbled through the layer phlegm on the contact device; $\tau$ is the contact time between the phases; $\delta$ is the thickness of the diffusion boundary layer, the gas-glycol; $\pi$ is the total pressure vapor (absolute pressure in the rectification tower); $P$ is the vapor pressure of the component in the liquid phase; and $y^{\prime}$ and $x^{\prime}$ are the molar fractions of the components in the vapor phase and liquid respectively.

We estimate the influence on the contact device of the parameters in the rectification process operating in the mass transfer of the component from the vapor phase into the liquid. For this purpose, based on the data given in $[1,2,9$, $10]$, a dependence on the operating parameters of the rectification process is derived from expression (1).

According to $[1,2,9]$ the molecular diffusion coefficient in the diffusion boundary layer, the radius and the surface of bubbles and vapor bubbling through the layer phlegm, the time of contact between the phases depending upon the temperature and pressure in the rectification system may be expressed as follows: 


$$
\begin{aligned}
& D=k_{1} \cdot \frac{T^{3 / 2}}{\pi} \\
& a=k_{2} \cdot \frac{T^{1 / 3}}{\pi^{1 / 3}} \\
& S=k_{3} \cdot \frac{T^{2 / 3}}{\pi^{2 / 3}} \\
& \tau=k_{4} \cdot \frac{\pi}{T}
\end{aligned}
$$

where $k_{1}, k_{2}, k_{3}, k_{4}$ are the coefficients of proportionality; $T$ is the temperature of the interaction vapor phase and liquid on the contact device; and $a$ is the radius of the bubbles and vapor bubbling through the layer phlegm on the contact device.

On the basis of [10], the thickness of the diffusion boundary layer in expression (1) can be represented as follows:

$$
\delta=k_{5} \cdot \sqrt{D \cdot a \cdot \tau}
$$

where $k_{5}$ is the coefficient of proportionality.

On the basis of (2), (3) and (5) the expression for the thickness of the diffusion boundary layer (6) takes the form:

$$
\delta=k_{6} \cdot \frac{T^{5 / 12}}{\pi^{1 / 6}}
$$

where $k_{6}$ is the coefficient of proportionality.

Based on the derived relations (2), (5) and (7), expression (1) for the mass transfer $i$ component of the vapor to the liquid phase at the contact device dependent on the rectification column pressure and temperature in the rectification system can be represented as follows:

$$
M=k_{7} \cdot T^{3 / 4} \cdot \pi^{1 / 2} \cdot y_{i}^{\prime}
$$

where $k_{7}$ is the coefficient of proportionality.

Equation (8) shows that the mass transfer efficiency of the component from the vapor phase into the liquid on the contact device of the rectification tower can be accelerated due to the increase of the working pressure.

\section{The derivation of the expression for estimating the efficiency reinforcing the contact device of the rectification tower through its operating parameters}

From the consideration of the dynamics of the interaction bubble of the vapor phase with the layer phlegm on the contact device we can now estimate the efficiency of the contact device via the ratio between the mass transfer of components from the vapor phase into a liquid and the volume of vapor phase 


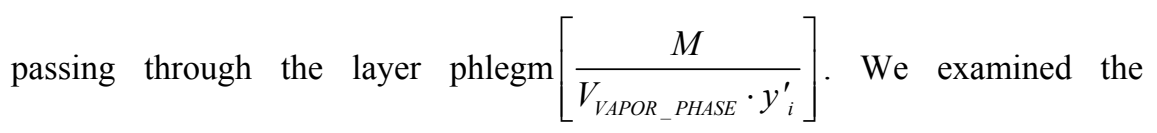
dependence of this relation on the operating parameters (temperature and pressure) of the rectification tower. The calculation of the volume of vapor phase was based on the Mendeleev-Clapeyron equation. The mathematical description of the mass transfer of the component between the vapor and liquid phases on a contact device was found by considering expression (8). The relationship $\left[\frac{M}{V_{\text {VAPOR_PHASE }_{-} \cdot y_{i}^{\prime}}}\right]$ can then be written in the following form:

$$
\frac{M}{V_{\text {VAPOR_PHASE }} \cdot y_{i}^{\prime}}=K \cdot \frac{\pi^{3 / 2}}{T^{1 / 4}}
$$

where $K$ is the coefficient of proportionality.

Relation (9) shows that the efficiency of mass transfer of the components from the vapor phase to the liquid on the contact device of the rectification tower may be expressed as the ratio $\left[\frac{M}{V_{V_{A P O R_{-}} P H A S E} \cdot y_{i}^{\prime}}\right]$. This dependence can be used to assess the efficiency of the contact device of the rectification tower as the operating parameters are changed over a wide range.

\section{Considering the influence of surfactants on the light fractions boil-off from the bottom product of the rectification tower}

We determined the dynamics of the process of boiling of organic liquids so that we could investigate the alternative methods of solving the problem of increasing the speed of light boiling fractions the bottom product of the rectification tower.

Heat balance boiling of organic liquids may be described by the expression:

$$
Q=G \cdot \lambda+\sigma \cdot S
$$

where: $Q$ is the amount of heat supplied to the volume liquid in unit time $t$; $G$ is the amount of liquid boiled off from its volume per time unit; $\lambda$ is the heat of the boiling liquid; $\sigma$ is the surface tension at the interface between the liquid and vapor phases in the volume of the saturated liquid; $S$ is the total surface of the vapor bubbles formed in the volume of the saturated liquid.

From equation (10) it follows that the amount of liquid boiled off per unit time from the volume may be expressed as follows:

$$
G=\frac{Q-\sigma \cdot S}{\lambda} .
$$

This equation shows that the process of boiling off of liquid with a constant heat supply to its volume may be accelerated by reducing the surface tension at the interface between the vapor and liquid phases. 
In the research $[11,12]$ a method for reducing the surface tension at the gas-liquid interface by introducing a surfactant was proposed. The surfactant used was a nickel salt with synthetic fatty acids, $\mathrm{Ni}(\mathrm{RCOO})_{2}$ (where $\mathrm{R}=\mathrm{C}_{9}-$ $\mathrm{C}_{15}$ ).

Having an input surface material of an amount of not more than $50 \mathrm{ppm}$ in the volume of liquid decreases the surface tension at the air interface to $50 \%$. The results of the testing systems were shown for example for glycol-air, n-hexaneair, air-oil and straight-run gasoline fraction-air interfaces.

We carried out a study on the effect of reducing the surface tension at the interface of vapor bubbles in the liquid volume on the rate of boiling of individual hydrocarbons and multicomponent liquids. Surface tension can be reduced by introducing a surfactant $\mathrm{Ni}(\mathrm{RCOO})_{2}$. We found the optimal concentration of input $\mathrm{Ni}(\mathrm{RCOO})_{2}$ based on studies conducted to determine the maximum reduction of the surface tension at the interface of the organic liquid and air at a temperature of $20^{\circ} \mathrm{C}$. N-hexane, cyclohexane and benzene were used as individual hydrocarbons. Distillation was carried out by using a flask placed in an ultrathermostat. Constant heat input was provided by using the ultrathermostat. The distillation temperature was maintained at $6^{\circ} \mathrm{C}$ above the boiling point of the individual hydrocarbon. The distillation in each case was 30 minutes. Shaim oil and straight-run gasoline fraction (TBP $-180^{\circ} \mathrm{C}$ ) were used a multi-component fluids. The distillation method used an Engler distillation test at $100^{\circ} \mathrm{C}$. The distillation of the listed hydrocarbon liquids with surfactant and supplied heat intensity is analogous to the distillation without surfactant. The results are shown in Tables 1 and 2.

Table 1: Data on influence of the surfactant on the boiling rate of individual hydrocarbons.

\begin{tabular}{|c|c|c|c|c|c|c|c|}
\hline \multirow{2}{*}{$\begin{array}{c}\text { Name of } \\
\text { hydrocarbon }\end{array}$} & \multirow{2}{*}{ 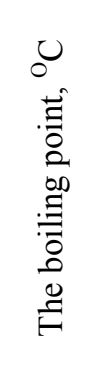 } & \multirow{2}{*}{ 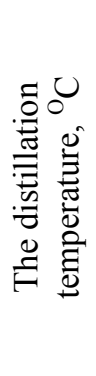 } & \multirow{2}{*}{ 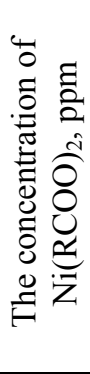 } & \multicolumn{2}{|c|}{$\begin{array}{c}\text { The surface } \\
\text { tension at the } \\
\text { hydrocarbon-air } \\
\text { interface at } 20^{\circ} \mathrm{C} \text {, } \\
\mathrm{mN} / \mathrm{m}\end{array}$} & \multicolumn{2}{|c|}{$\begin{array}{l}\text { The relative rate of } \\
\text { boiling of } \\
\text { hydrocarbon, } \\
\text { units }\end{array}$} \\
\hline & & & & 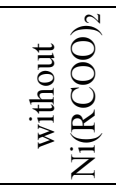 & 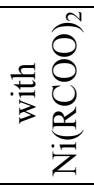 & 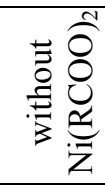 & 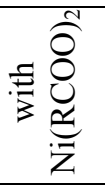 \\
\hline \multirow{3}{*}{ n-hexane } & 68.74 & 75,00 & 5.0 & 18.49 & 13.84 & 1.00 & 1.85 \\
\hline & 68.74 & 75,00 & 10.0 & 18.49 & 11.61 & 1.00 & 2.58 \\
\hline & 68.74 & 75,00 & 15.0 & 18.49 & 14.68 & 1.00 & 1.63 \\
\hline \multirow{3}{*}{ cyclohexane } & 82.98 & 89,00 & 5.0 & 26.57 & 18.18 & 1.00 & 1.43 \\
\hline & 82.98 & 89,00 & 10.0 & 26.57 & 16.91 & 1.00 & 2.34 \\
\hline & 82.98 & 89,00 & 15.0 & 26.57 & 20.67 & 1.00 & 1.68 \\
\hline \multirow{3}{*}{ benzol } & 80.10 & 86,00 & 5.0 & 28.84 & 21.19 & 1.00 & 1.69 \\
\hline & 80.10 & 86,00 & 10.0 & 28.84 & 18.73 & 1.00 & 2.10 \\
\hline & 80.10 & 86,00 & 15.0 & 28.84 & 23.67 & 1.00 & 1.35 \\
\hline
\end{tabular}


Table 2: Data on the influence of the surfactant on the boiling rate of hydrocarbonaceous liquid by distillation by Engler's method.

\begin{tabular}{|c|c|c|c|}
\hline \multirow{2}{*}{$\begin{array}{c}\text { The } \\
\text { hydrocarbonaceous } \\
\text { liquid }\end{array}$} & \multirow{2}{*}{\begin{tabular}{|c|} 
The \\
concentration \\
of $\mathrm{Ni}(\mathrm{RCOO})_{2}$, \\
ppm
\end{tabular}} & \multicolumn{2}{|c|}{$\begin{array}{c}\text { The relative rate of boiling of hydrocarbon } \\
\text { units }\end{array}$} \\
\hline & & without $\mathrm{Ni}(\mathrm{RCOO})_{2}$ & with $\mathrm{Ni}(\mathrm{RCOO})_{2}$ \\
\hline \multirow{3}{*}{$\begin{array}{l}\text { Straight-run } \\
\text { gasoline fraction } \\
\left(\mathrm{TBP}-180^{\circ} \mathrm{C}\right)\end{array}$} & 7.00 & 1.00 & 1.76 \\
\hline & 9.25 & 1.00 & 2.06 \\
\hline & 12.00 & 1.00 & 1.62 \\
\hline \multirow{3}{*}{ Shaim oil } & 32.00 & 1.00 & 1.82 \\
\hline & 37.75 & 1.00 & 2.15 \\
\hline & 43.00 & 1.00 & 1.76 \\
\hline
\end{tabular}

The data in Tables 1 and 2 show that reduction of the surface tension at the interface between the vapor and liquid phases results in acceleration of the light fraction boiling of the organic liquid volume at a constant heat input. This is caused by facilitation of the formation of vapor bubbles in the fluid volume and their growth. When using of the concentration of surface-active substance $\mathrm{Ni}(\mathrm{RCOO})_{2}$ the best values were obtained, giving an acceleration of the boiling of the light fraction of the organic liquid of at least twice the average.

\section{The results of the industrial testing of the proposed methods to improve the efficiency of the rectification process}

Our conclusions on the effect of pressure changes in the system of rectification on the rectification sharpness of the components and the efficiency of the contact devices were tested by considering the operation of the rectification tower for various purposes. Examples of this testing are shown in Tables 3-7.

Table 3: The results of exploitation of the reducing tower by change of pressure in the distillation system.

\begin{tabular}{|c|c|c|c|c|c|}
\hline The name of the indicator & \multicolumn{5}{|c|}{ The value of the indicator } \\
\hline Pressure, MPa: & \multicolumn{5}{|c|}{} \\
\hline working value & 0.27 & 0.35 & 0.40 & 0.45 & 0.50 \\
\hline permissible value & 0.63 & 0.63 & 0.63 & 0.63 & 0.63 \\
\hline Temperature of, ${ }^{\mathrm{O}} \mathrm{C}:$ & 146 & 148 & 148 & 148 & 148 \\
\hline overhead product & 232 & 233 & 234 & 233 & 234 \\
\hline bottoms product & 220 & 220 & 220 & 220 & 220 \\
\hline input of raw material & & & & \\
\hline Rectification sharpness, ${ }^{\mathrm{O}} \mathrm{C}:$ & 36 & 24 & 12 & 3 & minus 4 \\
\hline TBP-100 & \multicolumn{2}{|c|}{}
\end{tabular}


840 Energy Production and Management in the 21st Century, Vol. 2

Table 4: The result of exploitation of the atmospheric tower by change of pressure in the distillation system that separates the reduced crude oil.

\begin{tabular}{|c|c|c|c|c|c|}
\hline The name of the indicator & \multicolumn{5}{|c|}{ The value of the indicator } \\
\hline \multicolumn{6}{|l|}{ Pressure, MPa: } \\
\hline working value & 0.15 & 0.20 & 0.25 & 0.30 & 0.35 \\
\hline permissible value & 0.45 & 0.45 & 0.45 & 0.45 & 0.45 \\
\hline \multicolumn{6}{|l|}{ Temperature of, ${ }^{\mathrm{O}} \mathrm{C}$ : } \\
\hline overhead product & 133 & 132 & 132 & 132 & 132 \\
\hline output of fraction $180-240$ & 180 & 180 & 181 & 180 & 182 \\
\hline output of fraction $240-290$ & 242 & 241 & 240 & 242 & 243 \\
\hline output of fraction $290-360$ & 318 & 319 & 320 & 320 & 320 \\
\hline bottoms product & 337 & 337 & 338 & 338 & 338 \\
\hline input of raw material & 355 & 355 & 355 & 355 & 355 \\
\hline \multicolumn{6}{|l|}{ Rectification sharpness, ${ }^{\mathrm{O}} \mathrm{C}$ : } \\
\hline$\frac{100-180}{180-240}$ & 32 & 13 & 4 & minus 3 & minus 8 \\
\hline$\frac{180-240}{240-360}$ & 43 & 24 & 7 & minus 1 & minus 4 \\
\hline
\end{tabular}

Table 5: The result of exploitation of the atmospheric tower by change of pressure in the distillation system that separates the crude oil.

\begin{tabular}{|c|c|c|c|c|c|}
\hline The name of the indicator & \multicolumn{5}{|c|}{ The value of the indicator } \\
\hline \multicolumn{6}{|l|}{ Pressure, MPa: } \\
\hline working value & 0.15 & 0.20 & 0.25 & 0.30 & 0.35 \\
\hline permissible value & 0.53 & 0.53 & 0.53 & 0.53 & 0.53 \\
\hline \multicolumn{6}{|l|}{ Temperature of, ${ }^{\mathrm{O}} \mathrm{C}$ : } \\
\hline overhead product & 139 & 141 & 141 & 143 & 144 \\
\hline $\begin{array}{l}\text { output of fraction } \\
180-360\end{array}$ & 226 & 226 & 227 & 228 & 228 \\
\hline bottom product & 332 & 332 & 333 & 332 & 334 \\
\hline input of raw material & 348 & 348 & 348 & 348 & 348 \\
\hline \multicolumn{6}{|l|}{ Rectification sharpness, ${ }^{\mathrm{O}} \mathrm{C}$ : } \\
\hline$\frac{\text { TBP-180 }}{180-360}$ & 34 & 16 & 4 & $\begin{array}{c}\text { minus } \\
4 \\
\end{array}$ & minus 11 \\
\hline
\end{tabular}

The examples given in Tables 3-7 show that increasing the operating pressure in the range of 1.3-2.0 times achieves a clear separation of hydrocarbon distillates or mixtures thereof in the rectification. In each case, the operating pressure needed in the rectification tower to achieve rectification sharpness of hydrocarbon distillates or mixtures was selected experimentally. The presented examples show that the operating pressure required to achieve a clear distillate 
Table 6: The result of exploitation of the stabilization tower of the fraction TBP -180 by change of pressure in the distillation system.

\begin{tabular}{|c|c|c|c|c|c|c|c|}
\hline The name of the indicator & \multicolumn{7}{|c|}{ The value of the indicator } \\
\hline Pressure, MPa: & \multicolumn{7}{|c|}{} \\
\hline working value & 0.80 & 1.00 & 1.20 & 1.40 & 1.60 & 1.80 \\
\hline permissible value & 2.40 & 2.40 & 2.40 & 2.40 & 2.40 & 2.40 \\
\hline Temperature of, ${ }^{\circ} \mathrm{C}:$ & 67 & 68 & 68 & 67 & 69 & 70 \\
\hline overhead product & 190 & 190 & 192 & 190 & 192 & 191 \\
\hline bottoms product & 8.5 & 8.5 & 8.5 & 8.5 & 8.5 & 8.5 \\
\hline The ratio irrigation & 1.89 & 1.23 & 0.71 & 0.34 & 0.16 & 0.07 \\
\hline Rectification sharpness, \% wt.: & 1.89 & 1.23 & 0.71 & 0.34 & 0.16 & 0.07 \\
\hline $\begin{array}{c}\text { content of } \mathrm{C}_{4} \mathrm{H}_{10} \\
\text { in stabilize fraction BP-180 }\end{array}{ }^{\circ} \mathrm{C}$ & 2.24 & 1.47 & 0.78 & 0.26 & 0.19 & 0.06 \\
\hline $\begin{array}{c}\text { content of } \mathrm{C}_{5} \mathrm{H}_{12} \text { in overflow of } \\
\text { stabilization tower }\end{array}$ & & & & & \\
\hline
\end{tabular}

Table 7: The result of the exploitation of the deethanization tower by change pressure in the distillation system.

\begin{tabular}{|c|c|c|c|c|c|}
\hline The name of the indicator & \multicolumn{5}{|c|}{ The value of the indicator } \\
\hline Pressure, MPa: & \multicolumn{5}{|c|}{} \\
\hline working value & 2.6 & 2.8 & 3.0 & 3.2 & 3.4 \\
\hline permissible value & 4.5 & 4.5 & 4.5 & 4.5 & 4.5 \\
\hline Temperature of, ${ }^{\mathrm{O}} \mathrm{C}$ & \multicolumn{5}{|c|}{} \\
\hline \begin{tabular}{|} 
overhead product \\
minus \\
12
\end{tabular} & $\begin{array}{c}\text { minus } \\
10\end{array}$ & $\begin{array}{c}\text { minus } \\
8\end{array}$ & $\begin{array}{c}\text { minus } \\
6\end{array}$ & $\begin{array}{c}\text { minus } \\
5\end{array}$ \\
\hline bottoms product & 84 & 85 & 87 & 87.5 & 89 \\
\hline Rectification sharpness, \% wt.: & & & & \\
\hline $\begin{array}{c}\text { content of } \mathrm{C}_{3} \mathrm{H}_{8} \text { in gas of } \\
\text { deethanization }\end{array}$ & 1.85 & 1.17 & 0.61 & 0.27 & 0.10 \\
\hline $\begin{array}{l}\text { content of } \mathrm{CH}_{4}+\mathrm{C}_{2} \mathrm{H}_{6} \text { in broad } \\
\text { fraction of light hydrocarbons }\end{array}$ & 0.72 & 0.55 & 0.34 & 0.19 & 0.06 \\
\hline
\end{tabular}

hydrocarbon or mixtures does not exceed the upper limit of the allowable operating current technological parameter for the machine.

The results were obtained by accelerating the boiling hydrocarbon fluids by adding a surfactant to the operation as discussed with reference to the atmospheric tower.

The experiment on the effect of the input of the surfactant on the rate of light fraction boiling of residual oil was carried out by the atmospheric distillation of crude oil. The input surfactant $\left(\mathrm{Ni}(\mathrm{RCOO})_{2}\right)$ introduced into the atmospheric column feed stream was based on a potential content of the fuel oil concentration of $37.75 \mathrm{ppm}$. Evaluation of the influence of the surfactant on the intensity of the light fraction boiling oil taken from oil in the bottom of the atmospheric tower 
was carried out by changing the selection of light fraction of the potential content in the oil. In the experiment, the technological parameters of the atmospheric tower were maintained at a constant. The experimental results are shown in Table 8.

Experimental studies show that the introduction of a surfactant $\left(\mathrm{Ni}(\mathrm{RCOO})_{2}\right)$ in an atmospheric tower feed stream based on the potential content of fuel oil increases the extraction of light fractions of petroleum capacity at $4.5 \% \mathrm{wt}$. under the existing technological systems of the device.

Table 8: Data on the effect of surfactant on the selection of the light fraction from atmospheric distillation of crude oil capacity.

\begin{tabular}{|l|c|c|c|}
\hline \multirow{2}{*}{ The name of the indicator } & \multicolumn{3}{|c|}{ The value of the indicator } \\
\cline { 2 - 4 } & $\begin{array}{c}\text { the literary } \\
\text { data } *\end{array}$ & $\begin{array}{c}\text { without } \\
\mathrm{Ni}(\mathrm{RCOO})_{2}\end{array}$ & $\begin{array}{c}\text { with } \\
\mathrm{Ni}(\mathrm{RCOO})_{2}\end{array}$ \\
\hline $\begin{array}{l}\text { Pressure in the } \\
\text { rectification tower, } \mathrm{MPa}\end{array}$ & $>0.15$ & 0.1 & 0.1 \\
\hline $\begin{array}{l}\text { Temperature of input raw } \\
\text { material, }{ }^{\mathrm{O}} \mathrm{C}\end{array}$ & $>360$ & 350 & 350 \\
\hline $\begin{array}{l}\text { the temperature in the } \\
\text { bottom part, }{ }^{\mathrm{C}}\end{array}$ & $>360$ & 338 & 336 \\
\hline $\begin{array}{l}\text { Selection of light fractions } \\
\text { of potential content in raw } \\
\text { materials, \% wt. }\end{array}$ & $88-92$ & 93.2 & 97.7 \\
\hline
\end{tabular}

* The literature data taken from [6].

\section{Conclusion}

From the above work, it follows that the rectification sharpness of products of the rectification tower can be accomplished by changing the processing method for their exploitation and the use of surfactants.

Increasing the pressure in the rectification system provides an increased efficiency of mass transfer of the components between the vapor and liquid phases on the contact devices. The consequence of this is to achieve a rectification sharpness of the components in the reinforcement of the rectification tower. In each case, the required operating pressure in a rectification tower to achieve the rectification sharpness of hydrocarbon distillates or mixtures was selected experimentally. The required value of this parameter is not more than double the existing operating pressure in the distillation tower and must not exceed the available technological regulations.

It is important to know the mode of operation of rectification towers in estimating the efficiency of contact devices. It is proposed that there is a dependence of the evaluation of the efficiency of the contact device of rectification towers through mass transfer of components on the ratio of the vapor and liquid phases and the volume of vapor which passes via the layer phlegm at the contact device. 
The input of surfactant in a certain concentration in the feed stream rectification columns based on the content of the residue provides a potential twofold increase in the rate of light fractions boil-off from the bottom part of the rectification tower.

The surfactant provided consists of the use of nickel salts of synthetic fatty acids, $\mathrm{Ni}(\mathrm{RCOO})_{2}$ (where $\mathrm{R}=\mathrm{C}_{9}-\mathrm{C}_{15}$ ).

Implementation of the proposed technical solutions into the operation of the rectification tower will improve the refinement of the quality of motor fuels produced and the approach towards the project value of the material balance of oil and gas refineries.

\section{References}

[1] Kafarov, V.V. Fundamentals of mass transfer, [in Russian], second edition processing, High School: Moscow, 1972.

[2] Bagaturov, S.A. The theory and calculation of distillation and rectification, [in Russian], third edition revised, Chemistry: Moscow, 1974.

[3] Aleksandrov, I.A. Distillation and rectification in refining, [in Russian], Chemistry: Moscow, 1981.

[4] Berlin, A.M., Gorechenkov, V.G., Volkov, N.P. Processing of oil and natural gases, [in Russian], Chemistry: Moscow, 1981.

[5] Skoblo, A.I., Molokanov, Yu. K, Vladimirov, A.I. Processes and equipment for refineries and petrochemical plants, [in Russian], third edition revised and expanded, LLC "Nedra business center": Moscow, 2000.

[6] Manovjan, A.K. Technology of primary processing of oil and natural gas, [in Russian], second edition, Chemistry: Moscow, 2001.

[7] Emidganov, R.T. Bases of technological calculations in oil refinery, [in Russian], Chemistry: Moscow, 1965.

[8] Tregubov, A.M. Theory of distillation and rectification, [in Russian], third edition, GosTopTehIzdat: Baku, 1958.

[9] Dgankoli, D. Physics, [in Russian], translation from English, Mir: Moscow, 1989.

[10] Levich, V.G. Physicochemical hydrodynamics, [in Russian], second edition, Gosudarstvennoe izdatelstvo physico-mathematical literature: Moscow, 1959.

[11] Ikanin, S.A., Magaril, R.Z., Improve the process of drying of natural gas [in Russian]. Izvestia vyssih ucebyh zavedenij, Neft I gas: Tyumen, 4, pp. 86-90, 2005.

[12] Rogalev, M.S., Magaril, R.Z., Klauzner Sh-G. M. Aspects of the primary distillation of crude oil, [in Russian]. Izvestia vyssih ucebyh zavedenij, Neft I gas: Tyumen, 4, pp. 73-78, 2008. 